\title{
Водные объекты в АПК и их эксплуатация
}

\section{О.Н. Черных, Н.В. Ханов}

Представлены общие сведения о гидротехнических природоохранных сооружениях: плотинах, прудах, мельницах, некоторых актуальных вопросах строительства, экологической реконструкции, восстановления и эксплуатации прудов и сооружений на них в современном сельском хозяйстве.

Ключевые слова: природоохранные гидротехнические сооружения, пруд, водоток, орошение, водоснабжение, рекреация.

территориях с.- х. назначения водные объекты включают в себя искусственные (водохранилища) или естественные (озера, моря, болота) водоемы, водотоки (соответственно каналы, лотки, трубы, канавки, перепады и реки, ручьи, водопады и пр.) и подземные (родники, ключи, колодцы, скважины и пр.). Искусственный водоем - это хранилище воды, созданное человеком, с целью ее сохранения, накопления и дальнейшего использования (рис. 1).

Для разумного и традиционного для русского крестьянина использования воды местного стока для орошения, обводнения, разведения рыбы, водоплавающей птицы и обеспечения водой населенных пунктов для различных хозяйственных нужд (водоснабжения), в том числе и пожаротушения, спорта, купания и пр. целесообразно строительство прудов на ложбинах, балках, малых реках. Прежний облик российской деревни трудно представить без пруда, украшающего местный пейзаж, который и обеспечивал водой хозяйственные потребности населения. Их размещали непосредственно в деревне, либо на околице, а на выгонах или в поле соответственно устраивали пруды для водопоя скота

Чаще всего искусственными водоемами в сельской местности являются пруды, создаваемые путем перегораживания плотиной русла реки, ручья, балки, лога [1]. Русловые пруды сооружают обычно в руслах рек, ручьев, оврагов и балок, не имеющих развитой поймы (рис. 2.). Они располагаются последовательно один за другим, каскадом. В этом случае каждый пруд имеет свою плотину, па-

водковый водосброс, а часто и донный водоспуск (рис. 3).

Плотина-запруда, перегораживая реку, увеличивая ее вглубь и вширь, собирает и поднимает воду на необходимую высоту, создает напор, который затем используется в нужных целях: борьбы с обмелением водотока, созданием судоходных глубин, выработки электрического тока, забора воды для водоснабжения населения или в канал для орошения полей, водохранилища для рыболовства, рекреации и пр. Плотина, образовав водохранилище, в большинстве случаев, не останавливает совсем движение реки, но замедляет ее течение, что даже при нормальной работе указанных выше отде-

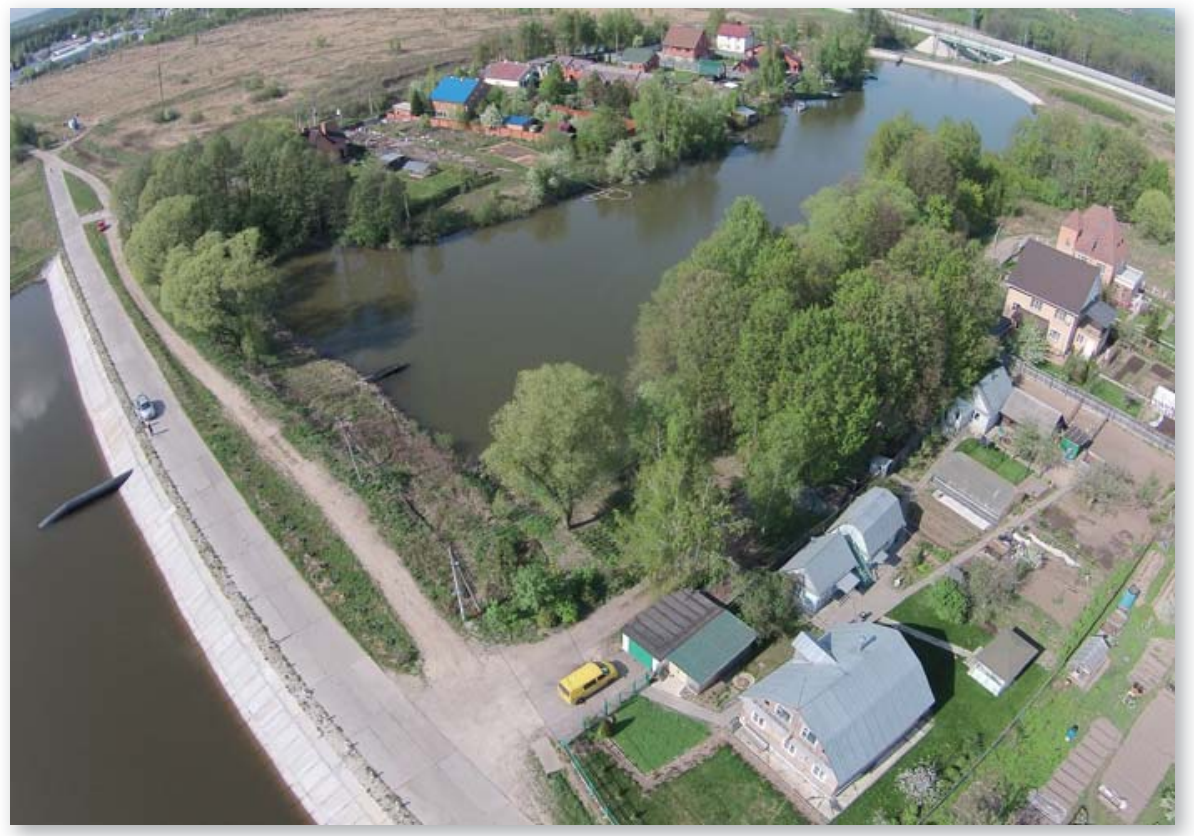

Рис. 1. Вид речного гидроузла с грунтовой плотиной и закрытым сифонным водосбросом (снимок с воздуха квадрокоптером). Фото предоставлено ФГБУ «Управление "Спецмелиоводхоз"

льных гидротехнических сооружений (далее ГТС), приводит к заметным изменениям окружающей среды. Трансформация речных экосистем происходит не только в верхних, нижних и средних звеньях речной сети, воздействию также подвергаются приустьевые участки рек (дельты и эстуарии), которые представляют собой весьма сложные экосистемы.

Для сброса излишков воды из пруда обычно устраивают открытые либо закрытые водосбросы или водосливные плотины для опорожнения - донные водовыпуски.

В основном в России всегда строили грунтовые плотины (земляные, каменно-земляные и каменно-набросные) - более 80\%, реже деревянные и бетонные, что характерно и для мировой практики, а в современных подпорных сооружениях помимо этого гидротехники используют бетон/железобетон, сталь, пластмассу, композитные и ткано-пленочные материалы.

Около 1890 года плотины впервые стали использовать для выработ- 


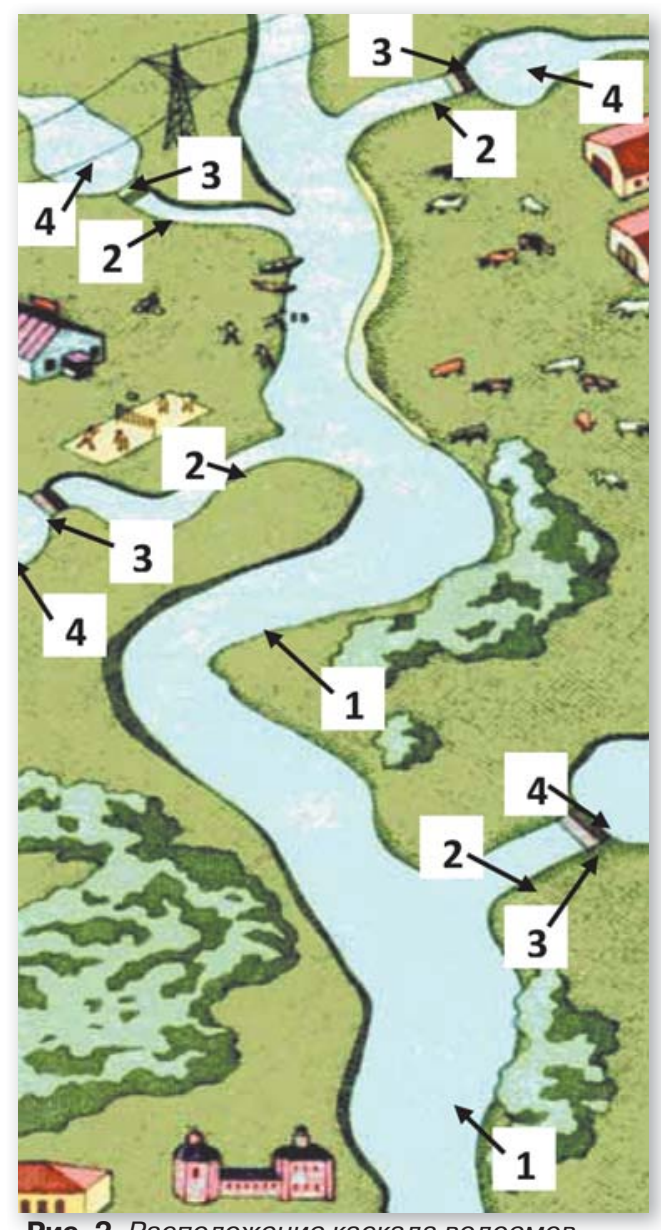

Рис. 2. Расположение каскада водоемов разного назначения на притоках реки [8]:

1 - основной водоток; 2 - притоки; 3 плотины; 4 - пруды

ки электроэнергии. «Крупной» или «большой» плотиной Международная комиссия по крупным плотинам, образованная в 1928 году, определяет плотину с высотой более 15 м от ос-

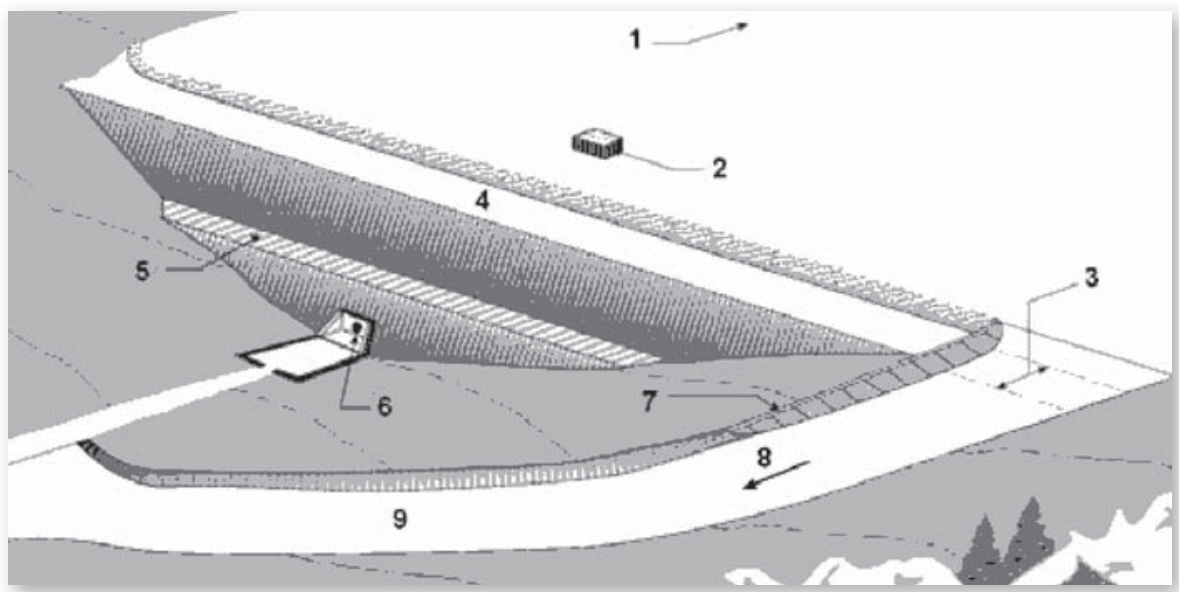

Рис. 3. Схематичный вид со стороны нижнего бьефа рекреационного гидроузла [2]: 1 - водохранилище; 2 - входной оголовок донного водоспуска с сороудерживающей решеткой; 3 - нерегулируемый водосливной порог берегового водосброса; 4 - гребень грунтовой плотины; 5 - берма дренажного банкета; 6 - выходной оголовок донного водоспуска; 7 - берма направляющей дамбы; 8 - направление течения; 9 - отводящий канал. ли, лестничные спуски, набережные, причалы или эллинги, фонтанные устройства, очистные сооружения и пр.).

Регулируемые паводки на запруженных реках несут с собой экономические выгоды для населения нижнего бьефа, если его жизнь зависит от природных ресурсов, тесно связанных с паводковыми водами (пастбищное животноводство, сельское хозяйство на пойменных землях и рыболовство). Регулирование водного режима может быть также оценено с точки зрения упущенной выгоды. Цена отказа от удачного альтернативного строительству плотины варианта может быть больше или меньше в зависимости от стоимости вырабатываемой электроэнергии, подаваемой на нужды орошения воды и т.д. Ряд исследований показал, что нередко регулирование водного режима гидроузлом и предотвращение наводнений может приносить немалую экономическую прибыль, однако в других случаях ущерб из-за отказа от альтернативного варианта все же не удается покрыть никакими доходами, полученными в районах нижнего бьефа. Потенциал контролируемых паводков часто ограничен самой конструкцией водосбросных устройств, накоплением наносов в водохранилище и руслах рек, а также развитием инфраструктуры на пойменных землях, затапливаемых при паводках.

Еще в древности за прудами, дамбами и плотинами регулярно ухаживали «водяные люди», обязательно готовя их к весеннему паводку и ремонтируя после его прохождения. Чтобы поддерживать необходимый объем воды в пруде, его периодически очищали от наносов и ила, который использовали как удобрение. Сегодня реабилитация водных объектов проводится с использованием эколого-приближенных технологий, позволяющих произвести очистку дна водоема от ила и скопившегося мусора, а также провести берегоукрепительные, благоустроительные, озеленительные работы, зарыбление и заселение их гидробионтами [2, 3]. В качестве проектируемых мероприятий по снижению воздействия плотин на рыбное хозяйство часто используются рыбопропускные сооружения.

При эксплуатации прудов необходимо для повышения его продуктивности и самоочищающей способности обеспечивать водообмен, спуская примерно раз в три года воду из ко- 


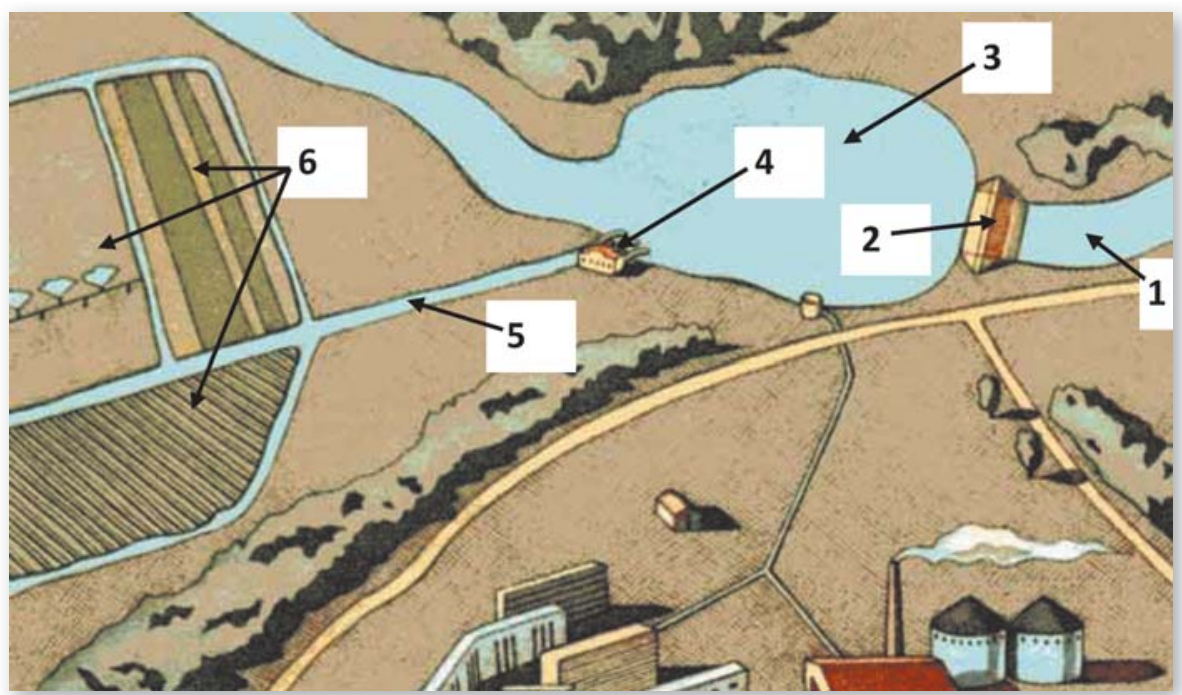

Рис. 4. Мелиоративный гидроузел на запруженном водотоке [8]: 1 - водоток; 2 - плотина; 3 - водохранилище (пруд); 4 - насосная станция; 5 - магистральный канал; 6 - орошаемые территории

паного пруда, или при помощи ряда специальных мелиоративных методов нормализовывать хорошее качество воды и почвы $[2,4]$. Чем больший объем воды будет забираться из пруда для нужд сельского хозяйства тем лучше будет освежение воды. Специальные природоохранные мероприятия: аэрирование водного объекта, современные биологические, химические и механические способы очистки воды от зарастания, заиления и загрязняющих веществ, поступающих со стоком с прилегающей к водному объекту территории, устройство биоплато, установка плавающих фонтанных устройств, а в некоторых случаях и устройство водопровода подпитки, удаление мусора, в том числе и со дна разного рода зацепов (хворост, пни, коряги, карчи и пр.), рациональное природоприближенное берегоукрепление обеспечат нормальный вылов рыбы.

Природные ландшафты России всегда были связаны с рекреационной стороной жизни населения. Яркий пример рекреационного ландшафта - Петровское-Разумовское, территория РГАУ-МСХА имени К.А. Тимирязева [5]. Русские усадьбыXVI-XVIII веков, в том числе и их водные объекты, требуют скорейшего восстановления [6].

В целом как правило, предусматривается три варианта восстановления водоемов и водотоков в зависимости от объема намечаемых работ в соответствии с уже существующим состоянием, характеризуемым отклонением от природного режима: полное природоприближенное экологическое благоустройство [7]. Если пруд предназначен для купания, то на берегах устраивают пляжную зону, оборудуют мостки, раздевалки, если для рыборазведения - участки для подкормки и ужения рыбы. Возле противопожарных прудов готовят надежные подъездные пути и площадки для водозаборной техники (насосов). Полный комплекс мероприятий (вариант 1) включает:

- формирование оптимального профиля, обеспечивающего требуемый природный режим водоема и водотока, дноуглубление, очистка и частичная выемка донных загрязненных иловых отложений, при необходимости устройство гидроизоляции;

- оформление и берегоукрепление;

- посадка водной и околоводной растительности, водоохранное озеленение поймы;

- анализ и разработка способов повышения качества воды в конкретном водном объекте, в частности, устройство устьевых и русловых

- оформление водовыпусков;

- противоэрозионные и противооползневые мероприятия;

- ликвидация последствий разливов нефтепродуктов и исключение или отвод других загрязняющих стоков;

- установка датчиков уровней воды в створах гидротехнических сооружений, организация постов контроля загрязнения малых прудов и рек; восстановление; частичное природоприближенное восстановление; биоплато;
- уборка мусора, удаление крупногабаритных и затопленных предметов;

- зарыбление;

- устройство мостиков, пешеходных и эксплуатационных дорожек, смотровых площадок, пляжных и купальных зон, мест для платной рыбной ловли, водопоя скота, каптаж родника и устройство колодца и пр.;

- установка гидротехнических элементов на берегу, плавающих островах и акватории водного объекта, повышающих естественный потенциал его самоочищения после реконструкции с учетом новых технологий, уменьшающих дефицит кислорода и кислотность воды, дегазацию и соблюдение требуемого $\mathrm{pH}$, создающих потокообразование, циркуляцию и движение воды: плавающих фонтанных агрегатов и дополнительных аэрирующих устройств; очистных плавающих сооружений с возможным перемещением в любое место акватории, и др.;

- разработка и применение компенсационных мероприятий ущерба водным биоресурсам, наносимого при проведении строительных и восстановительных работ, рыбоводномелиоративных мероприятий;

- формирование экосистемы на берегу: обустройство околоводной и прилегающей территории к пруду или ренатурируемого участка водотока.

В мировой практике в настоящее время орошение является наиболее распространенным видом безвозвратного потребления пресной воды, т.к. оно необходимо для производства продуктов питания и обеспечения продовольственной безопасности. Орошение проводится примерно на одной пятой части всех с.- х. земель мира, и на долю такого земледелия приходится около 40\% мировой с.- х. продукции. Половина крупных плотин в мире построена преимущественно для орошения. Приблизительно 30-40\% из 268 млн га орошаемых земель во всем мире зависят от плотин. При этом установлено, что орошение с использованием подземных вод, как правило, приводит к более высокой урожайности при одинаковом расходе воды изза более эффективного управления этими ресурсами. Есть и проблемы, сопутствующие орошаемому земледелию, которые проявляются на пятой части всей площади орошаемых земель: засоление почв и заболачивание территорий, что ограничивает урожайность выращиваемых культур 
и количество их видов. В других регионах чрезмерная откачка воды из скважин истощает пласты подземных вод, снижает их уровень и постоянно повышает затраты на водозабор. Это создает дополнительные трудности, особенно для мелких землевладельцев.

В соответствии с Российским регистром гидротехнических сооружений (РРГТС), плотины высотой ниже 15 м относятся к низконапорным и сооружениям IV класса опасности (99\%), именно они чаще всего используются в агропромышленном комплексе РФ. В состав современного водохозяйственного комплекса РФ входит более 65 тыс. ГТС, включая плотины, дамбы, защитные валы, каналы, трубопроводы, судоходные шлюзы, насосные станции и пр., из которых 4,5 тыс. - безхозяйные ГТС, которые не имеют собственника, или собственник которых неизвестен, либо это ГТС, от права собственности на которые собственник отказался. Из общего количества поднадзорных Ростехнадзору комплексов ГТС основное их количество находится в ведении Министерства сельского хозяйства РФ - 1481 ед., в ведении Росводресурсов - 884 ед., прочие - 21710 ед. При этом в ведении Минсельхоза РФ находится 2,2 тыс. регулирующих гидроузлов, включающих более 300 ГТС, 236 водохранилищ, из них преимущественно небольшие водохранилища (объемом 1-10 млн м³-156 ед.) и прудов для мелиоративных и животноводческих комплексов, рыборазведения, эксплуатирующихся для местных, в том числе хозяйственно-бытовых и рекреационных нужд. Абсолютное большинство водоподпорных ГТС представлены плотинами малых и средних водохранилищ, многие из которых эксплуатируются с шестидесятых годов прошлого века без реконструкции, ремонта и являются объектами повышенной опасности для населения и объектов экономики. На данный момент 97\% ГТС отработали свой нормативный срок (для ГТС IV класса он составляет 50 лет). При этом в 2015 году зарегистрировано более 15 тыс. ГТС, имеющих опасный уровень безопасности (15\% от общего количества зарегистрированных комплексов ГТС), и около 400 тыс. (4,7\% за счет постановки на учет бесхозяйных - 3,2\%), поднадзорных Ростехнадзору.
В государственной собственности находится около 1\% всех ГТС. Только на территории Московской области из более чем 1,5 тыс. ГТС на данный момент от 49\% до $68 \%$ гидроузлов в зависимости от района являются безхозяйными. Из них 87\% требуют капитального ремонта. Бесхозяйные ГТС представляют собой преимущественно сельскохозяйственные пруды для мелиоративных и животноводческих комплексов, небольшие дамбы, эксплуатирующиеся для местных нужд и не являющиеся источниками потенциальной опасности, у 69\% сейчас назначение - рекреационное. Указанные ГТС были построены ликвидированными или обанкротившимися сегодня с.x. организациями для решения местных задач, как правило, без составления проектно-сметной документации. Такие ГТС не были поставлены на учет как недвижимое имущество, сведения о них не вносились в РРГТС. Больше всего малых водохранилищ и прудов сельскохозяйственного и рыбоводного назначения было построено с 1960 по 1980 годы. Наиболее густая сеть прудов и водохранилищ сельского назначения (до 30 водоемов на 1 млн га) находится в Центрально-Черноземном, Северо-Кавказском, Поволжском, южных областях Центрального, Волго-Вятского, Уральского экономических районов $[1,4,8]$. По разным причинам в последнее время около 50\% из них утратили свое хозяйственное назначение или оно характеризуется как «неопределенное».

Анализ мировой практики мелиоративной с.- х. гидротехники показывает, что иногда более качественные проектные решения играют значительную роль в предотвращении или минимизации воздействий плотин на окружающую среду. Задачи восстановления, сохранения и экологической реабилитации водных объектов решаются в комплексе с мероприятиями по благоустройству территорий, прилегающих к ним, которые формируют качество и состояние самих водных объектов, ландшафт сельской, поселковой или городской среды, обеспечивая их полноценный рекреационный и природный потенциал. Поэтому вопрос о необходимости строительства нового водоема или ГТС, реконструкции и проведения регламентных работ, ликвидации, потерявшего свое водохозяйственное назначение водного объекта, или его консервации, должен решаться анализом эколо- гических последствий для питающего водотока, экологической опасности для окружающих территорий, профессиональным проведением работ по технической и биологической рекультивации ложа и береговой полосы водного объекта.

В заключении отметим еще один важный аспект использования водных сооружений на территории современного агрокомплекса. Использование энергии речных потоков началось в России еще в глубокой древности. Уже в XVI в. водяной двигатель в России использовали не только для переработки с.- х. продукции, но и в металлургии, добыче полезных ископаемых, обработке камня. Вторая половина XVII века и XVIII век - золотое время водяных двигателей, в России и в мире. В России в конце XVIII века действовало несколько тысяч гидросиловых установок, главным образом на горных заводах. Начиная с шестидесятых годов XX века, после перехода сельского хозяйства на централизованное электроснабжение, они были заброшены и разрушены [9].

Сегодня новую жизнь гидросиловым установкам дает малая гидроэнергетика. Микро- и мини-ГЭС постепенно получают распространение, особенно в труднодоступных с.- х. районах, где затруднено централизованное электроснабжение. Конечно, здание водяной мельницы и энергию падающей воды чаще всего используют уже не для помола зерна, а для выработки локального электричества, организации экотуризма, как объект историко-культурного наследия, изучения крестьянского быта, создания нового центра рекреации и коммерции [3]. Чтобы не прерывалась связь веков, целесообразно восстановить водяные мельницы, особенно в исторических местах. Кроме того, восстановление мельниц будет способствовать и сохранению природных ландшафтов.

Выводы. Оценка альтернативных вариантов использования водных объектов на с. - х. территориях требует следующего:

- улучшение эффективности и продуктивности существующих оросительных систем с учетом существующих водных объектов и их гидротехнических сооружений до стадии планирования и внедрения новых;

- адаптация и расширение применения местных и традиционных решений в области водопользования, мелиоративной гидротехники, природоохранных и природоприближен- 
ных гидротехнических сооружений и мероприятий;

- более согласованное управление поверхностными и подземными водными ресурсами;

- необходимость защиты (или восстановления) естественного функционирования дельт, пойм малых водотоков, водоемов и водосборных бассейнов для более устойчивой и высокой продуктивности традиционных видов природопользования на этих территориях;

- повышение рекреационной роли водных объектов и развитие событийного экотуризма.

\section{Библиографический список}

1.Шабанов А.Д. Пруды в сельском хозяйстве М. Колос, $1977.192 \mathrm{c}$.

2.Волшаник В.В., Пешнин А.Г., Радионов В.Б., Юрченко А.Н., Амирова Н.Н., Доркина И. В. Инженерные пути решения проблемы улучшения экологического состояния прудов и малых рек. // Безопасность энергети ческих сооружений. Научно- технический и производственный сборник ОАО «НИИЭС». М., 2003. Вып. 12. С. $367-377$

3.Черных О.Н., Румянцев И.С., Алтунин В.И. Использование водяных мельниц при восстановлении и экологической реабилитации водных систем. М
ФГОУ ВПО МГУП, 2010. 369 с.

4.Бабиков Б.В. Гидротехнические мелиорации. СПб.: Лань, 2005. 300 c.

5.Черных О.Н. Русская усадьба в выпускных работах кафедры гидротехнических сооружений ФГБОУ ВО «РГАУ-МСХА имени К.А. Тимирязева» // Вестник учебно-методического объединения по образованию в области природообустройства и водопользования. 2018. № 11. С.166-174.

6.Алтунин В., Волшаник В., Пьявкин С., Черных О. Вода льется - и мелет, течет, пилит, кует и откачивает воду // Коммерсант-Наука. 2015. № 3. С. 44-45.

7.Черных О.Н., Алтунин В.И., Сабитов М.А. Типизированные приемы экологического восстановления малых рек Москвы (на примере р. Сетунь) // Природообустройство. 2015. № 3. С. 66-72.

8.Разумов Г.А. Плотины. М.: Дет.лит., 1988. 55 с.

9.Черных О.Н., Волшаник В.В. Роль водяных мельниц В воссоздании исторических ландшафтов // Природообустройство. 2017. № . 4. С. 47-55.

\section{Об авторах}

Черных Ольга Николаевна, канд. техн. наук, доцент кафедры «Гидротехнические сооружения». E-mail:gtsmgup@mail.ru

Ханов Нартмир Владимирович, доктор техн. наук, зав. кафедрой «Гидротехнические сооружения». E-mail: nvkhanov@yahoo.com Институт мелиорации водного хозяйства и строительства имени
А.Н. Костякова ФГБОУ ВО РГАУМСХА имени К.А. Тимирязева

Water bodies in rural areas and their use

O.N. Chernykh, PhD, associate professor

of the Hydraulic Structures Department.

E-mail: gtsmgup@mail.ru

N.V. Khanov, DSc, head of the Department

of Hydrotechnical Structures.

E-mail:nvkhanov@yahoo.com.

Institute of Land Reclamation of Water

Management and Construction named after

A.N. Kostyakova Federal State Budgetary

Educational Establishment of the RSAU-

MSHA named after K.A. Timiryazev

Summary. The general information about the hydrotechnical environmental structures: weirs, ponds, mills, some pressing issues of construction, environmental reconstruction, restoration and operation of ponds and structures on them in modern farming is presented.

Keywords: environmental hydraulic structures, pond, watercourse, irrigation, water supply, recreation.

\section{Партнерство АО «Щелково Агрохим" и ресторатора Антона Винера}

АО «Щелково Агрохим» и ресторатор Антон Винер объединяютсядлясозданиясоциальноориентированного бизнеса в России.

11 октября 2019 года на стенде АО «Щелково Агрохим» в рамках выставки «Золотая осень» был подписан меморандум «О партнерстве в создании сертифицированной системы контроля продуктов питания и социально ориентированном бизнесе» между Антоном Винером, совладельцем более 25 ресторанов и ресторанных проектов, и Салисом Добаевичем Каракотовым, генеральным директором компании АО «Щелково Агрохим». После процедуры подписания меморандума, состоялся брифинг, на котором Салис Добаевич Каракотов и Антон Винер рассказали о ближайших планах и глобальной стратегии партнерства.

«Эти вопросы стали отправной точкой нашего общего диалога о партнерстве с АО «Щелково Агрохим» инновационной компанией в области аграрных технологий.

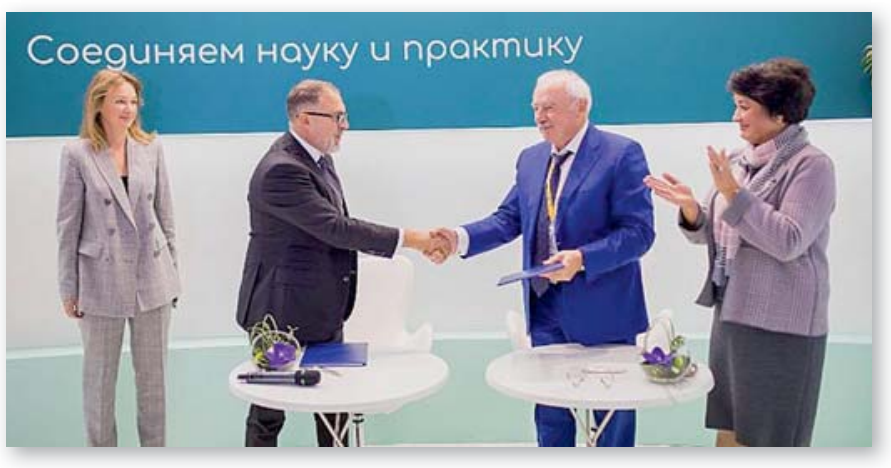

Мы решили создать коллаборацию, главной миссией которой станет стопроцентный контроль качества всех продуктов питания, поставляемых в наши рестораны», - комментирует партнерство известный ресторатор Антон Винер.

«Нам не все равно, из чего и как готовится еда в ресторанах. И мы несем равную с компаниями по переработке пищевой продукции ответственность за качество исходного сырья. Работая с крупнейшими холдингами страны, мы выработали для себя жесткие критерии производственных процессов, потому что понимаем, что будущее за теми, кто ответственно относится к здоровью и экологии», - высказывает свою позицию Салис Добаевич Каракотов, генеральный директор компании АО «Щелково Агрохим».

Партнерское объединение компании «Щелково Агрохим» и известного ресторатора Антона Винера - это логичное сотрудничество в рамках современных реалий создания социально ориентированного бизнеса. Это партнерство даст АО «Щелково Агрохим» возможность развития новых направлений, а также слаженную дистрибуцию качественной продукции. А для ресторанов, совладельцем которых является Антон Винер, такой союз предоставит возможность круглогодично и бесперебойно получать гарантированно качественные продукты питания. В итоге все окажутся в выигрыше, а больше всего - потребители и любители здоровых экологически чистых продуктов питания.
К.К. Павлов Фото автора 